\title{
How are maps used in research? An exploratory review of PhD dissertations
}

\author{
Serena Coetzee ${ }^{\mathrm{a}, *}$, Sanet Carow ${ }^{\mathrm{b}}$, Lourens Snyman ${ }^{\mathrm{a}}$, \\ ${ }^{a}$ Department of Geography, Geoinformatics and Meteorology, University of Pretoria - serena.coetzee@up.ac.za, \\ lourens.snyman@up.ac.za \\ ${ }^{b}$ Department of Geography, University of South Africa- sanetpc@unisa.ac.za \\ * Corresponding author
}

\begin{abstract}
:
Maps are a powerful medium for communicating research. Tools for analysing geospatial data and preparing maps are now readily available and widely used in research. Despite this, concerns are being raised over the quality of maps produced with online and desktop mapping products. As academics and supervisors of postgraduate students, we conducted an exploratory study to determine if and how these concerns apply to maps in $\mathrm{PhD}$ dissertations. We reviewed just over 1,000 dissertations published in 2015 and 2017 at three universities. Maps for indicating locations or study areas were used in a diverse range of topics, confirming our reliance on maps to communicate information about geographic space. Maps that communicated scientific results were prevalent in the natural sciences and in the humanities, and in these cases, the dissertations included a large number of maps. We provide a qualitative description of problems identified in the dissertations, which highlight challenges with the accurate and responsible presentation of scientific results in maps. The accumulation of minor inaccuracies on maps, especially if one result is based on another, can have serious consequences for scientific knowledge production. Future work could review maps in $\mathrm{PhD}$ dissertations to inform guidelines for preparing and evaluating maps to be included in dissertations.
\end{abstract}

Keywords: maps; cartography; $\mathrm{PhD}$ dissertations; communication; research

\section{Introduction}

Maps have the power to provide spatial context and to graphically represent and simplify complex phenomena. As such they are a powerful communication medium to contextualize research and to present complex scientific results. Maps convey meaning, primarily by graphic symbols that represent or stand for something else (Tyner, 2014). When reading maps, people form impressions of places and are influenced by the way the map is created (Peterson, 2014). Maps therefore also have the power to lead (and mislead) readers (Robinson, 2018), intentionally or unintentionally (Monmonier, 2018).

The last twenty years has seen a huge surge in geospatial data. Tools for analysing and visualizing such data are now readily available and are widely used in research. Concerns are being raised about the quality of maps produced with online and desktop mapping products (Wood, 1968; Medeiros, 2016; Kraak et al, 2018), and whether these maps accurately convey the information they present (Hay et al., 2013; Robinson \& Petchenik, 1975; Robinson 2018). As academics and supervisors of postgraduate students, we asked ourselves if and how these concerns apply to maps in $\mathrm{PhD}$ dissertations.

To find answers to our questions, we reviewed $\mathrm{PhD}$ dissertations published in 2015 and 2017 at three universities, with the following questions in mind: In which disciplines are maps used? For which purpose are the maps used, e.g. to indicate location (where something is/happens), to provide spatial context, or to present scientific results? Did the author prepare the maps or were they sourced from a third party? We also identified maps with interesting applications as well as maps with obvious errors for further discussion and to consider whether there is a reason for concern regarding the quality of maps in PhDs.

In the next section of the paper, we describe how the review of maps in $\mathrm{PhD}$ dissertations was done. In section 3 we present the results of this review. In section 4, the results are discussed in the context of a scientific literature review, focussing on challenges related to communicating scientific research results through maps in $\mathrm{PhD}$ dissertations. Section 5 concludes.

\section{Method}

Published $\mathrm{PhD}$ dissertations from three universities namely the University of Pretoria, Texas Tech University and the University of Zurich formed part of this study. The universities were chosen through convenience sampling because the authors are familiar with the universities or had a contact person at these universities. For this exploratory study, the ranking or other characteristics of the universities were not considered for inclusion in the study. The sampling method proved to be useful because there were subtle differences in the structure and organization of $\mathrm{PhD}$ dissertations between the three universities, which our contact persons explained to us. Many of the PhDs from the University of Zurich and the 
Texas Tech University consisted of a compilation of published articles, while most dissertations from the University of Pretoria had a more traditional dissertation layout consisting of various chapters. The contact persons at the universities also assisted us with downloading the published $\mathrm{PhDs}$ in a bundle instead of one by one. This saved a considerable amount of time.

The three universities are located on three different continents namely North America, Europe and Africa. Each of the three universities offers a module in cartography or a module related to cartography, such as an internet mapping module. This suggests that students at these universities had an equal opportunity to attend at least one module in cartography or a related field or had access to a person that could assist or advise them in compiling or sourcing maps for the use in a $\mathrm{PhD}$. However, we do not know whether PhD candidates made use of this opportunity.

$\mathrm{PhD}$ dissertations published in 2015 and 2017 were included in the review, except those not available due to an embargo. The dissertations for 2016 were not included in this study as we wanted the study to extend over a longer period. We searched through each dissertation to determine if maps were included. The dissertation title, abstract and name of the department were recorded for dissertations with maps, as well as the following: the number of maps; how a map contributes to the research; and whether the map was prepared by the author or sourced from a third party. A figure that contained more than one map was only counted once. If the same map was used in more than one chapter in the dissertation, it was also only counted once. If the dissertation indicated that a map had been modified or adapted from another source, it was recorded as prepared by the author.

Sketches of areas and building plans were not regarded as maps in this study. Remotely sensed images, such as satellite images and aerial photographs, were also not regarded as maps unless the author used an image as a background and plotted/displayed other features on top of the image.

Names of faculties differed from one university to another. To be able to analyse the data meaningfully, the faculties were categorized into the following disciplines: Business, Economics and Informatics; Education; Engineering; Health Sciences; Humanities; Law; Natural Sciences; and Veterinary Sciences.

The statistics of dissertations in the review are provided as absolute numbers, not normalized according to student numbers per faculty or university, as this information is not readily available. The findings of this study are presented for all the dissertations reviewed and not per university because the authors were interested in the results as a whole.

In the qualitative results section, we discuss three maps from dissertations with interesting or unexpected application fields and conclude with a selection of problems in maps that could mislead the user or could make it difficult to interpret the map. We identified maps based on our experience as supervisors and lecturers. The aim was not to conduct a comprehensive quantitative review of problems in all maps but to provide a qualitative description of problems for further investigation. Where problems on maps are discussed, the $\mathrm{PhDs}$ candidates were not mentioned or referenced, as we did not wish to expose them.

\section{Results}

\subsection{Quantitative results}

We searched through $1,071 \mathrm{PhD}$ dissertations that were published by the three universities in 2015 and 2017. Most dissertations were published in Humanities (340 - 32\%), followed by Natural Sciences $(277-26 \%)$ and Education $(138-13 \%)$. See Figure 1 .



Figure 1. PhD dissertations per faculty $(\mathrm{n}=1071)$.

Compared to the number of PhDs that were published, the number of dissertations that included at least one map was relatively low: $126(12 \%$ of 1,071$)$.

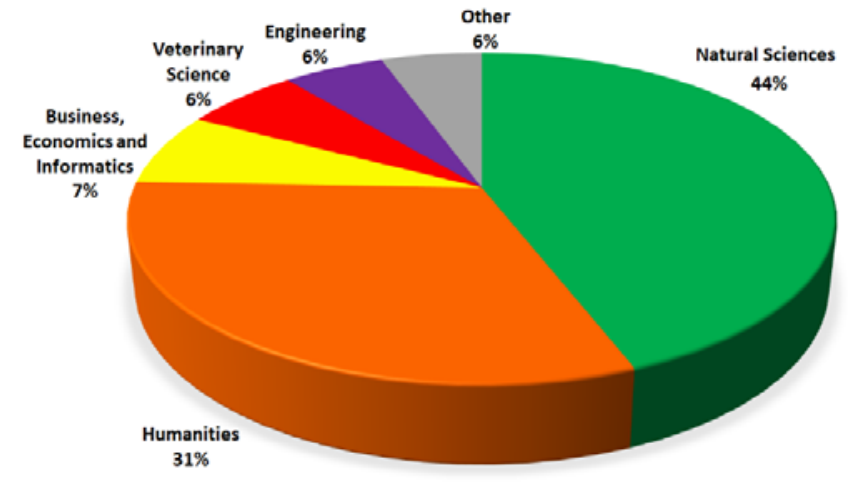

Figure 2. PhD dissertations with at least one map, per faculty $(n=126)$.

Even though most dissertations were published in the Humanities, most dissertations with maps were in the Natural Sciences $(56-44 \%)$, followed by Humanities (40 - 40\%), nine dissertations with maps in Business, Economics and Informatics. Only seven dissertations each in Veterinary Science and Engineering included maps, five in Education and only one dissertation from the Health Sciences had a map (included under 'other'). See Figure 2. 
The highest prevalence of maps in dissertations was also in Natural Sciences and Humanities (15\% on average); in the other categories $6 \%$ (on average) of the dissertations included a map.

Most maps (75\%) were created or modified by the author of the PhD while only a quarter of the maps were re-used from existing sources without modifying the map.

A total of 684 maps were included in the 126 dissertations. Figure 3 summarizes how the 684 maps contributed to communicating the $\mathrm{PhD}$ research to the reader. Maps were mostly used to communicate results to the reader, and to a lesser degree to contextualize the research in the literature review and to indicate locations (e.g. of sites or surveys in the method). The 349 maps to communicate results appeared in 39 dissertations, mostly in the Natural Sciences (159 maps in 21 dissertations), followed by Humanities (113 maps in 10 dissertations) and Veterinary Sciences (36 maps in 2 dissertations).

The dissertations that used maps in their results had an overall high number of maps included in the publication e.g. one dissertation used 54 of which 36 were created to communicate the analysis results. Dissertations that used a map to indicate a location, often had only a single map in the dissertation.

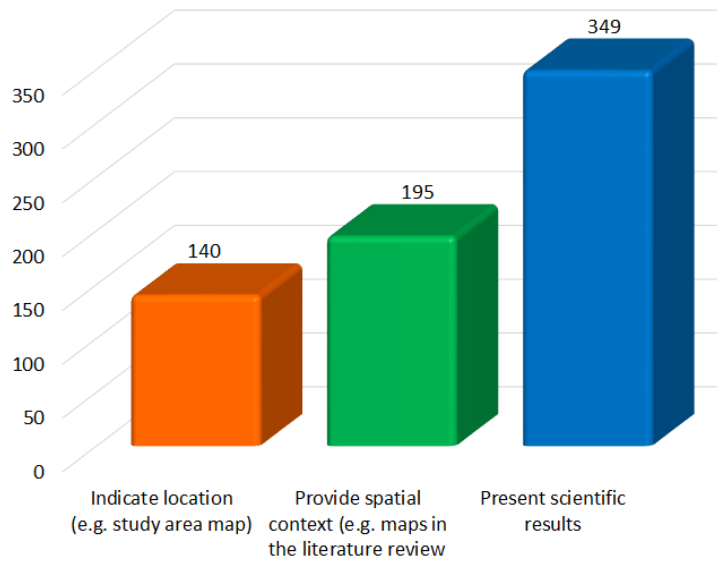

Figure 3. Contribution to communicating the $\mathrm{PhD}$ research

\subsection{Qualitative results}

To illustrate that maps are used widely, we describe three examples of maps from dissertations. A PhD study in Musical Arts by Ipsen (2017) focusses on orchestral conducting and contextualises how the experiences and exile of the composer, Fernando Garcia, influenced the creation of the symphonic tone poem "Las raices dela ira". The author includes two location maps in this study (see Figure 4): one of South America and one of the Nor Belles Astes district in Santiago, Chile. One could question whether the map portrays the experiences that influenced the composition of the music or whether they are merely 'screen dumps' from internet maps? The maps have no sense of place and do not incite any emotion that could give the reader a feeling of how the music was inspired. Musicians are artists in their own right and one could contemplate whether the musician felt frustrated by not being able to communicate through a map how the conductor of the music was inspired by his geographic surroundings.

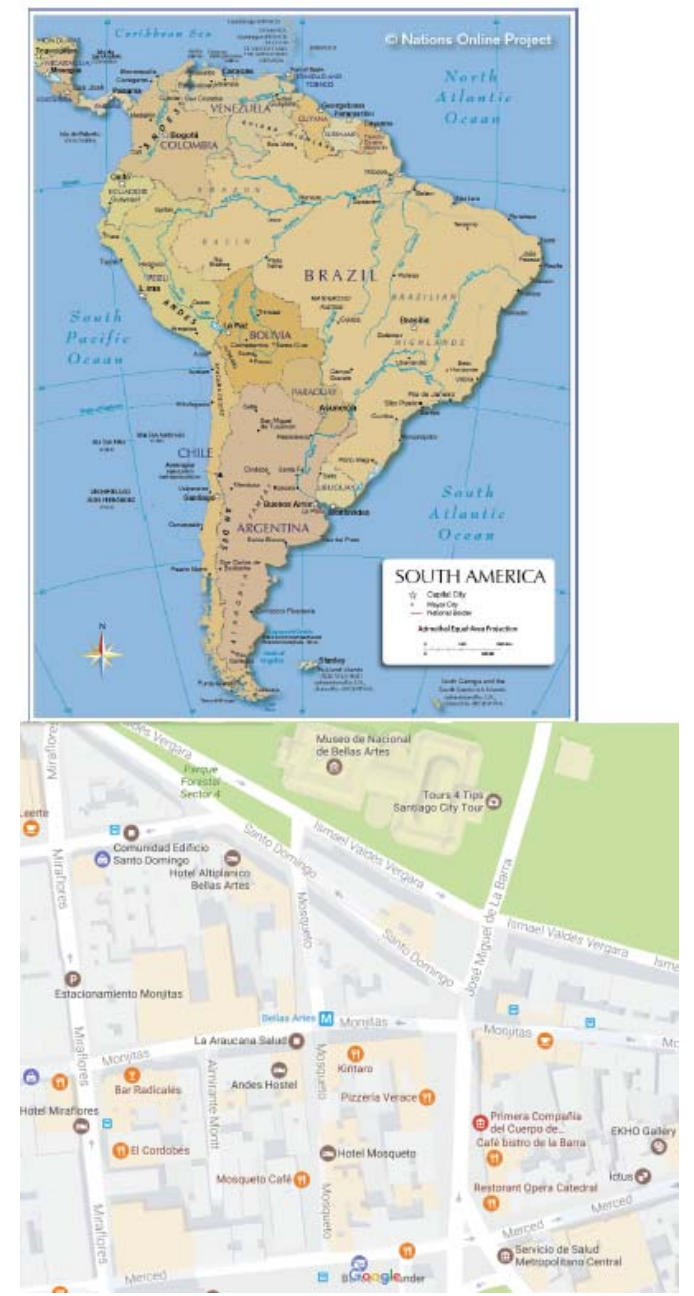

Figure 4. Example of a map from a $\mathrm{PhD}$ in Musical Arts. (The size and quality of the maps were adjusted for inclusion in this article.)

In a study on Labor Economics, Ruh (2017) included a sourced map that indicates the altitudes of municipalities in Austria (See Figure 5). The purpose of the map is to indicate the challenges experienced by communters due to large commute distances due to the presence of the Alps. Although we found the use of maps in a study of labour economics interesting, the map could be potentially misleading, as the legend includes ten different shadings of brown indicating altitude. No unit of measurement is indicated on the map and it is difficult to distinguish the various colours on the map. No orientation data, such as municipal names or the surrounding countries were added to the map. One could argue that a map to show the Alps as a barrier for commuters, would have portrayed the message clearer if municipal boundaries, major cities and connecting roads were included. 


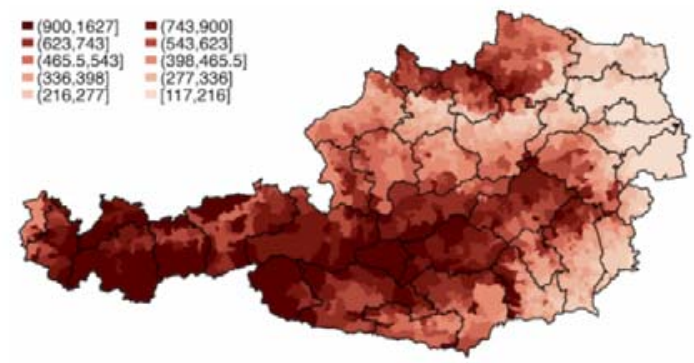

Figure 5: Example of a map from a $\mathrm{PhD}$ in Labor Economics (The size and quality of the map were adjusted for inclusion in this article.)

A philosophical study on what it means to be human (Doyle, 2017) includes a sourced map showing the distribution of the wood frog, Rana sylvatica (Doyle, 2017) (See Figure 6). This wood frog specie has the ability to utilize naturally occurring antifreeze compounds and proteins to survive in low temperatures. Due to the extremely low temperatures in the natural environment of the wood frogs, they may be frozen for up to two weeks with no breathing nor heartbeat. The possibility to do reversible freezing of humans is discussed in this context. While we found the topic of this dissertation intriguing, the question could be raised whether this map adds any value to the dissertation, as the focus of the philosophical study is about human beings and the distribution of the frog is only relevant at the fringes.

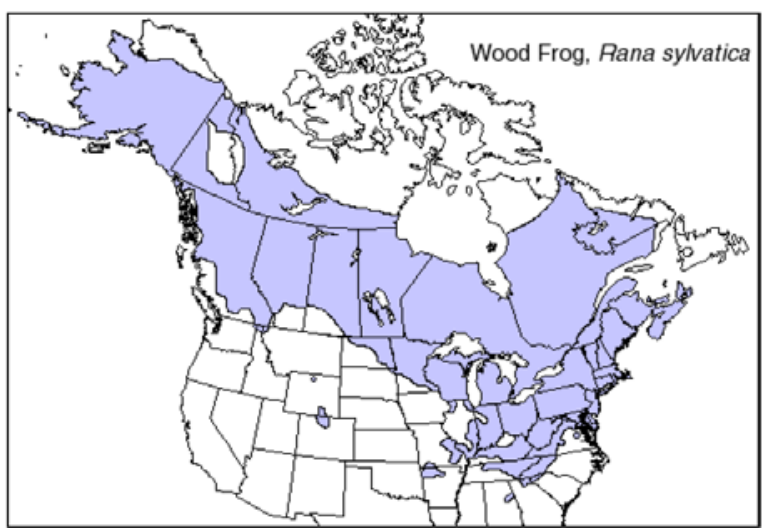

Figure 6: Example of a map from a PhD in Philosophy (The size and quality of the map were adjusted for inclusion in this article.)

While we did not count the errors or omissions on the maps and our intent was not to evaluate the compilation of the maps, we made some interesting observations that indicated that an in-depth study to analyse prolems on maps would be of interest and could inform guidelines for the use and compilation of maps in PhDs is needed. Many of the maps included in the dissertations to indicate location are difficult to interpret because they lack essential orientation data, such as country or place names, and any other features that could be used for orientation purposes, such as towns, roads or rivers. In one instance, a study area was indicated by coordinates of a single point, without any indication of the size of the area; some case study areas were also indicated without any orientation data to assist the reader of the map.

An indication of scale or distance on maps that communicate distance or size is a frequent omission on maps. This problem occurred on maps for indicating location, providing spatial context for the research and for presenting scientific results. Very few maps, if any, provided information about the projection, which could have provided some information for the interpretation of distance and size. Sometimes, a distance or size measurement was indicated on the map without any clue about the units of measurement.

We found maps with colour schemes that were inappropriate for the information that they represented, e.g. a sequential colour scheme (graduated colours) to present a qualitative data scheme of unordered values (or vice versa). Classification problems included overlaps in classes, e.g. an integer classification of three classes, 0 to $<=5,5$ to $<=10$ and $>=10$, where it is not clear whether 5 is in the first or the second class.

There are also examples of maps that were not prepared with GIS software at all, e.g. a thematic map in which the quantity for an area is added to an existing map with a callout (possibly done using software such as PowerPoint or Keynote). A choropleth map showing the quantity with a sequential colour scheme would have intuitively highlighted the area with the highest and lowest quantities. In a very horrific example, the width and height of maps are changed disproportionally to each other, resulting in maps that nicely fit onto a single page, but for which all the distances and areas are distorted. The author did not prepare the maps but obtained them from another source.

Maps in dissertations are of course embedded within text, which sometimes provides additional information for interpreting the map, and therefore one cannot evaluate the map in isolation. Nevertheless, for each of the problems identified in this section, we found examples where the text did not provide any additional information to assist with understanding the map.

\section{Discussion}

In the PhDs that we reviewed, maps are mostly used to communicate scientific results in the Natural Sciences and in the Humanities. However, maps are used widely: there was at least one $\mathrm{PhD}$ with a map in each of the categories, ranging as wide as the Musical Arts (Ipsen, 2017) and Theology (Mushayavanhu, 2017). While the maps in the latter did not present any scientific results, they confirm our (as humans) reliance on maps for communicating information about geographic space. Overall, a relatively small proportion of the reviewed dissertations included maps, but among those with maps, approximately a third used maps to present scientific results. Generally, the maps for indicating results or providing spatial context were copied or adapted from other sources. Where maps were used to present scientific results, the dissertation usually included quite a range of maps - up to 54 in one 
dissertation that we reviewed. Naturally, these maps were prepared by the authors.

While cartography as a qualification per se has declined, cartography and geovisualization are considered to be core knowledge areas of any GISc education, now and in the future (Hodza et al, 2015; UCGIS, 2019; Wallentin et al, 2015). The inclusion of maps in PhDs in a diverse range of applications suggests that cartography is not a skill that should be 'owned' solely by cartographers or geographic information scientists. Communicating geospatial information is a skill required by many more than that, and in the age of big (geospatial) data, the ability to communicate geospatial information is gaining ever more relevance and importance (UN-GGIM, 2013; Robinson \& Petchenik, 1975). However, it is not only those who make maps who require this ability. According to Kraak et al. (2018), the role of map users is also changing due to the popularization of internet services, crowdsourcing, open science and cloud mapping: the role of the cartographer has changed from that of a mapmaker to a maker of map design tools and the role of map users has changed to that of co-creators of online maps. At the same time, there has been a rapid and significant shift in power over the production of maps, with a major decline in the role of authoritarian state bureaucracies and the rise of a few unaccountable and profit-driven corporations (Dodge \& Perkins, 2015).

Today, anyone can make a map. However, any map does not necessarily communicate the geospatial information optimally. Many factors play a role when assessing how well a map is understood by the map reader (Cao et al, 2017; Xu, 2017; Rautenbach, 2017). Havelkova and Hanus (2018), for example, found that quantitative mapping methods were more challenging to interpret than thematic maps using qualitative or both qualitative and quantitative mapping methods. According to Mocnik and Fairbairn (2017), maps are good at representing geographic space, but texts have a stronger affordance of telling a story than maps. Telling stories is, however, important to make information more personal and to arrest the map user's attention. They compared maps to text to understand why texts are good at telling a story but conventional maps not. By making modifications to maps, they demonstrated how appropriate structural features of text media can be transferred to maps, making them more suitable for telling a story. Their proposed new concept for map design could be useful for PhD candidates who need to tell the story about their scientific results. A deep understanding of the making of maps requires a combination of different approaches, from the critical (text-oriented) to the ontogenetic (practice-oriented), from deconstruction to narrative ethnography, and from cultural contextual readings to subject-centred readings (Boria \& Rossetto, 2017).

The change from paper to digital media has impacted the way in which maps are prepared and read. Some maps, such as maps on smartphones with small screens or multimedia maps, have special requirements that traditional paper maps do not have (Tyner, 2014).
Research has improved our understanding of how information should be communicated in these new maps, e.g. in wildfire warning systems (Cao et al, 2017), transportation planning (Xu, 2017), digital humanities (Allen \& Queen, 2015), architecture (Cheng \& Perez-Kriz, 2014), virtual environments (Lokka et al, 2018) and tourism (Rosetto, 2012) to name a few. However, rapid and ongoing advances in software and hardware imply that for some of the newer maps little research has been carried out on the effectiveness of their design (Tyner, 2014). We found no evidence of digital era maps, such as animated maps, sound maps, haptic maps, multimedia maps or web maps. Most PhD dissertations are read on digital media these days, except for the $\mathrm{PhD}$ candidate, the supervisors and examiners, who probably read through paper versions of the dissertation. Yet, dissertations are still prepared as if they were to be read on an A4 page. Animated maps or interactive online maps are avoided, and design issues, such as suitable layout and dimensions for digital media, are not considered.

Through today's mass media, information spreads 'at the speed of light' - be it truthful information or false information. Fake science can spread so effectively that the false information remains in the pool of common knowledge (Starbird et al, 2014), even if corrected, as in the case of the now-retracted Lancet paper, which sparked the modern anti-vaccination movement (Eggertson, 2010; Rao \& Andrade, 2011). In a related case in cartography, the non-existent Sandy Island was included in many maps and data sets since the early 19th century, and only 'undiscovered' nearly two centuries later (Wikipedia, 2018). Robinson (2018) warns that fake maps may already be present in fake news sources and may have influenced recent political processes. How does one guarantee that maps in PhDs are devoid of any false information? To some extent the responsibility lies with the supervisor and examiners, ultimately, the $\mathrm{PhD}$ candidate has to take responsibility. However, as recent $\mathrm{PhD}$ plagiarism scandals have shown, it is difficult to detect plagiarism, let alone fake results made up by a PD candidate (The Local, 2015; Tudoroiu, 2017). Plagiarised or fake results presented in non-textual forms, such as maps, are even more difficult to uncover. StopFake makes use of novel digital means to question and detect false narratives in images. They claim that a photo presented as proof of Ukraine's guilt for the Malaysian Airline NH17 crash in 2014 was artificially constructed with photo manipulation software, among others, because a background fragment in the satellite photo exactly matched a patchwork of Yandex and Google Map satellite images from 28 August 2012 (Khaldarova \& Pantti 2016). Tyner (2014) points out that maps, especially those produced with GIS software, are often accepted at face value without questioning their veracity because a computer-produced map conveys a sense of accuracy. While a reviewer or examiner may question the content and source of a table, or a text, they may assume a map to be accurate until it is proven otherwise. 
While ethical scientists will not intentionally construe false information, the challenges of communicating geospatial information appropriately could lead to maps that unintentionally mislead their readers. Hay et al. (2013) raise concerns about the robustness and reliability of maps about infectious diseases. Their systematic review of maps showed that less than $5 \%$ of 174 clinically important infectious diseases have been mapped reliably, amongst others, because non-optimal mapping techniques were used for the data at hand. These same concerns can be raised about maps about scientific results in $\mathrm{PhD}$ dissertations. A countermeasure would be to provide $\mathrm{PhD}$ candidates and their supervisors with cartographic and GISc support and training in the same way that it is done for statistical and academic writing skills at many universities. In the least, there should be an awareness of the dangers of producing misleading maps.

However, even if maps are well prepared, map literacy remains a challenge (Rautenbach et al, 2017). In the end, there is also an onus on the map user to critically assess the accuracy of a map before using it, as so aptly stated by Monmonier (2018): "The wise map user is thus a skeptic, ever wary of confusing and misleading distortion conceived by ignorant or diabolical map authors".

In this study, we reviewed a small sample of dissertations published in English, German and French in 2015 and 2017 at the three universities. Even though the sample was small, we found that maps are used in a diverse range of application fields. We expect this to be the same worldwide because humans strongly rely on maps for communicating information about geographic space. In this small sample, we did not find obvious examples of maps that (most likely unintentionally) presented scientific results incorrectly. It would be interesting to review $\mathrm{PhDs}$ on a specific topic to better understand how reliable the scientific results deduced from their spatial analyses and maps are - similar to the study by Hay et al. (2013). Such a study could reveal how concerned we should be about unintentionally misleading maps in $\mathrm{PhD}$ dissertations and the impact of inappropriate mapping techniques on the accuracy of knowledge produced from spatial analyses and maps.

The maps discussed are not representative of all maps in this study. Their identification for the discussion was anecdotal and based on the experiences of the authors. However, the maps suggest that a more in-depth study to investigate the quality of maps used in $\mathrm{PhD}$ publications is needed.

\section{Conclusion}

Assuming that maps are accurate can have serious consequences. Extreme examples resulted in fatalities or even losing a battle and consequently a war that changed the course of Europe. The famous copying error on a map used by Napoleon Bonaparte caused him to lose the Battle of Waterloo. The fairly small details of a farm indicated in the wrong location on the battlefield and a non-existing bend in a road disoriented him so much that his artillery was aimed short of the British troops (Chazan, 2014). As recently as 2010, Nicaraguan troops unknowingly crossed the border into Costa Rica and planted a Nicaraguan flag on Calero Island belonging to Costa Rica. Consequently, the Organization of American States and the U.N Security Council were called in to mediate the dispute - only to find out that it was a mistake on Google maps (Swaine, 2010). The accumulation of minor inaccuracies on maps, especially if one result is based on another, could be equally dangerous to scientific knowledge production. The results of this study highlight challenges with accurately and responsibly presenting scientific results in maps. This can only be done if $\mathrm{PhD}$ candidates and their supervisors are aware of age-old cartographic principles, even if the maps are produced with modern-day software. It is therefore important to re-emphasize the importance of the principles of map design when $\mathrm{PhD}$ students incorporate maps in their dissertations. Many universities present postgraduate training in statistics and academic writing or incorporate these topics into their degree programs. Similar training is required for spatial analysis and mapmaking. A wide range of freely available training resources are available, but there are many challenges with providing not only cartographic support to postgraduate students and researchers at universities, but also support for finding the 'right' geospatial data for a particular research question (Coetzee et al. 2017).

\section{Acknowledgements}

We appreciate the help of Patricia Solís and Arzu Çöltekin with PhDs dissertations from the Texas Tech University and the University of Zürich, respectively.

\section{References}

Allen, T. and Queen, S. (2015). Beyond the Map: Unpacking Critical Cartography in the Digital Humanities. Visible Language, 49(3).

Boria, E. and Rossetto, T. (2017). The Practice of Mapmaking: Bridging the Gap between Critical/Textual and Ethnographical Research Methods, Cartographica $52: 1,2017$, pp. 32-48

Cao, Y., Boruff, B. J. \& McNiell, I. M. (2017). The smoke is rising but where is the fire? Exploring effective on-line map design for wildfire warnings. Nat Hazards, Volume 88, pp. 1473-1501.

Chazan, D. (2014). Map error hastened Napoleon's Waterloo defeat. The Telegraph. [Online] Available at: https://www.telegraph.co.uk/news/worldnews/europe/fr ance/11144216/Map-error-hastened-Napoleons-

Waterloo-defeat.html

[Accessed 25 April 2019].

Cheng, K. and Pérez-Kriz, S. (2014). Map Design for Complex Architecture: A User Study of Maps \& Wayfinding. Visible Language, 48(2).

Coetzee, S., Steiniger, S., Köbben, B., Iwaniak, A., Kaczmarek, I., Rapant, P., Cooper, A.K., Behr, F.-J., Schoof, G., Katumba, S., Vatseva, R., Sinvula, K. and Moellering, H. (2017). The Academic SDI - Towards 
understanding spatial data infrastructures for research and education. In: Advances in Cartography and GIScience - Selections from the International Cartographic Conference 2017, edited by Michael Peterson, Springer, pp99-113.

Dodge, M. and Perkins, C. (2015). Reflecting on J.B. Harley's Influence and What $\mathrm{He}$ Missed in "Deconstructing the Map", Cartographica 50:1, 2015, pp. 37-40.

Doyle, D. J. (2017). What does it mean to be human? Life, death, personhood and the transhumanist movement. $\mathrm{PhD}$ Dissertation, University of Pretoria.

Eggertson, L. (2010). Lancet retracts 12-year-old article linking autism to MMR vaccines. Can. Med. Assoc. J. 182 (4), ppE199-E200.

Hay, S.I., Battle, K.E., Pigott, D.M., Smith, D.L., Moyes, C.L., Bhatt, S., Brownstein, J.S., Collier, N., Myers, M.F., George, D.B., and Gething, P.W. (2013). Global mapping of infectious disease. Philosophical Transactions of the Royal Society B, 368: 20120250 DOI: $10.1098 /$ rstb.2012.0250

Havelková, L. and Hanus, M. (2018). The Impact of Map Type on the Level of Student Map Skills, Cartographica, 53(3), pp. 149-170.

Hodza, P., Schaab, G., Coetzee, S., Van der Merwe, F. and Vogt, B. (2015). Comparing proportional compositions of geospatial technology-related programs at three universities. South African Journal of Geomatics, 4(3):40-249.

Ipsen, R. T. (2017). Las raices de la ira: Fernando Garcia's Tone Poem \& Chilean Politics in Music Culture. PhD Dissertation, Texas Tech University.

Khaldarova, I. and Pantti, M. (2016). Fake News, Journalism Practice, 10:7, 891-901, DOI: 10.1080/17512786.2016.1163237

Kraak, M.-J., Ricker, B. and Engelhardt, Y. (2018). Challenges of Mapping Sustainable Development Goals Indicators Data. ISPRS International Journal of GeoInformation, 7(482), 15 pages. doi:10.3390/ijgi7120482.

Lokka, I. E, Çöltekin, A, Weiner J, Fabrikant S. I R Röcke, C. (2018). Virtual Environments as memory training devices in navigational tasks for older adults. Scientific reports, 8(10809), pp. 1-15.

Medeiros, D. (2016). Pretty Maps: Evaluating GIS Adoption of cartographic design standards and best practices in professional publicatons. Masters thesis. San Jose State University, August.

Mocnik, F.B. and Fairbairn, D. (2018). Maps telling stories? The Cartographic Journal, 55(1), pp.36-57.

Monmonier, M. (2018). How to lie with Maps. Chicago: The University of Chicago Press Books.

Mushayavanhu, D. (2017). An historical analysis of the Presbyterian Church of Southern Africa's socio-political and economical influence on Zimbabwe (1890-1990. $\mathrm{PhD}$ dissertation. University of Pretoria.
Peterson, M. P. (2014). Mapping in the Cloud. New York: The Guilford Press.

Rao, T.S.S., Andrade, C., 2011. The MMR vaccine and autism: sensation, refutation, retraction, and fraud. Indian J. Psychiatry 53(2), 95-96.

Rautenbach V., Coetzee, S. and Çöltekin, A. (2017). Development and evaluation of a specialized task taxonomy for spatial planning - A map literacy experiment with topographic maps. ISPRS Journal of Photogrammetry and Remote Sensing, Vol. 126, pp1626.

Rautenbach, V.-J. (2017). The use of 3D geovisualisations for urban design: The case of informal settlement upgrading in South Africa. PhD Dissertation: University of Pretoria.

Robinson, A.C. (2018). Elements of viral cartography, Cartography and Geographic Information Science, DOI: 10.1080/15230406.2018.1484304.

Robinson, A. H. \& Petchenik, B. B. (1975). The map as a communication system. In: Landmarks in Mapping: 50 years of The Cartographic Journal. New york: Routledge. Rossetto, T. (2012). 'Embodying the Map: Tourism Practices in Berlin', Tourist Studies, 12(1), pp. 28-51. doi: 10.1177/1468797612444192.

Starbird, K., Maddock, J., Orand, M., Achterman, P. and Mason, R.M. (2014). Rumors, false flags, and digital vigilantes: misinformation on twitter after the 2013 Boston Marathon bombing. In: iConference 2014 Proceedings, 9 pages. Available at: http://faculty.washington.edu/kstarbi/Starbird_iConfere nce2014-final.pdf [Accessed 19 April 209].

Swaine, J. (2010). Google maps error sparks invasion of Costa Rica by Nicaragua. The Telegraph. [Online] Available

at: https://www.telegraph.co.uk/news/worldnews/centralam ericaandthecaribbean/nicaragua/8117902/Google-mapserror-sparks-invasion-of-Costa-Rica-by-Nicaragua.html [Accessed 25 April 2019].

The Local. (2015). Another German minister hit by plagiarism row. [Online] Available at:

https://www.thelocal.de/20150927/germanys-defenceminister-in-plagiarism-row

[Accessed 25 April 2019].

Tyner, J.A., (2014). Principles of Map Design. The Guilford Press. ISBN-13: 978-1462517121

Tudoroiu, T., (2017). No, Prime Minister: PhD Plagiarism of High Level Public Officials. European Review, 25(4), pp. 623-641.

UCGIS (University Consortium for Geographic Information Science) (2019). GIS\&T Body of Knowledge. https://gistbok.ucgis.org/ [Accessed 30 April 2019].

UN-GGIM. (2013). Future trends in geospatial information management: the five to ten year vision. Second Edition. Produced by Ordnance Survey at the 
request of the United Nations Committee of Experts on Global Geospatial Information Management (UNGGIM).

Wallentin, G., Hofer, B. and Traun, C. (2015). Assessment of Workforce Demands to Shape GIS\&T Education, Transactions in GIS, 19(3):439-454.

Wikipedia. (2018). Sandy Island, New Caledonia. Available at: https://en.wikipedia.org/wiki/Sandy_Island,_New_Cale donia [Accessed 1 Dec 2018].

Wood, M. (1968). Visual perception and map design. In: Landmarks in Mapping: 50 years of The Cartographic Journal. New York: Routledge.

Xu, J. (2017). Map Sensitivity vs. map dependency: A case study of subway maps' impact on passenger route choices in Washington DC. Behavioural sciences, 7(72). 